\title{
Analisa dan Perancangan Aplikasi Cuti atau Ijin Karyawan Menggunakan Aplikasi Berbasis Web
}

\author{
Ananta Dicapriyo ${ }^{1}$, Elbino Andreas ${ }^{2}$, Firmansyah $^{3}$, Endar Nirmala ${ }^{4}$, Irpan Kusyadi ${ }^{5}$ \\ Teknik Informatika, Universitas Pamulang, Tangerang Selatan, Indonesia, 15417 \\ e-mail: ${ }^{1}$ elbinoan1501@gmail.com, ${ }^{2}$ anantadicapriyo1@ gmail.com, ${ }^{3}$ frmnsyah99@gmail.com, \\ ${ }^{4}$ dosen00216@unpam.ac.id, ${ }^{5}$ dosen00673@unpam.ac.id
}

Submitted Date: May $31^{\text {st }}, 2021$
Revised Date: July $06^{\text {th }}, 2021$
Reviewed Date: June $11^{\text {th }}, 2021$

Accepted Date: July 06 ${ }^{\text {th }}, 2021$

\begin{abstract}
Employees as one element in a company have rights and obligations to the company. One of the rights for employees is leave or permission for a certain time. The obligation of a company is to provide such leave or permission. In the process of applying for leave or employee permits so far, many use conventional processes. Conventional here means still using a form in the form of a sheet of paper leave or permission and must be sent to various parties for approval. This will take a long time and is not in line with the Go Green Program that is being carried out by many companies. Reduce, Re-use, Recycle and Replace are the four concepts of the Go Green program. Replacing the application for leave or permission that has been using a form (paper) by using a web-based application program is a step forward by the company to implement the Go Green concept. Web-based application programs in addition to reducing paper usage also do not require large physical data storage areas. This can be realized by making a webbased leave application which is certainly easier in terms of access to all employees. Meanwhile, data storage can be stored in cloud storage media. In this study, an application design will be made using UML (Unified Modeling Language) to be used as a reference during development. UML provides many diagrams, but in this study only a few diagrams were used. The results of the study indicate that application design using UML can facilitate communication between stakeholders, can make it easier for programmers to translate into programming languages. Using UML can reduce application creation errors and speed up completion.
\end{abstract}

Keyword: Analysis; Planning; UML; Applications; Web

\begin{abstract}
Abstrak
Karyawan sebagai salah satu unsur dalam suatu perusahaan memiliki hak dan kewajiban terhadap perusahaan. Salah satu hak bagi karyawan adalah cuti atau ijin dalam waktu tertentu. Kewajiban sebuah perusahaan adalah menyediakan cuti atau ijin tersebut. Dalam proses pengajuan cuti atau ijin karyawan selama ini banyak menggunakan proses secara konvensional. Konvensional di sini berarti masih menggunakan form berupa lembaran kertas cuti atau ijin dan harus dikirim ke berbagai pihak untuk persetujuaannya. Hal ini akan membutuhkan waktu yang lama dan tidak sejalan dengan Program Go Green yang sedang dilakukan banyak perusahaan. Reduce, Re-use, Recycle dan Replace adalah empat konsep program Go Green. Menggantikan pengajuan cuti atau ijin yang selama ini menggunakan formulir (kertas) dengan menggunakan program aplikasi berbasis web adalah satu langkah maju yang dilakukan oleh perusahaan untuk menerapkan konsep Go Green. Program aplikasi berbasis web selain mengurangi penggunaan kertas juga tidak memerlukan tempat penyimpanan data fisik yang besar. Hal ini dapat terwujud dengan membuat aplikasi cuti ijin berbasis web yang tentunya lebih menudahkan dalam hal akses ke seluruh karyawan. Sementara untuk penyimpanan data dapat disimpan dalam media penyimpanan cloud storage. Pada penelitian ini akan dibuat desain aplikasi menggunakan UML (Unified Modeling Language) untuk dijadikan acuan selama pengembangan. UML menyediakan banyak diagram, tetapi pada penelitian ini hanya digunakan beberapa diagram saja. Dari hasil penelitian menunjukkan bahwa desain aplikasi menggunakan UML dapat mempermudah komunikasi di antara stakeholder, dapat mempermudah
\end{abstract}


programmer menerjemahkan ke dalam bahasa pemrograman. Dengan menggunakan UML dapat mengurangi kesalahan pembuatan aplikasi dan mempercepat penyelesaian.

Kata Kunci: Analisa; Perancangan; UML; Aplikasi; Web

\section{Pendahuluan}

Cuti merupakan keadaan seorang karyawan dapat diijinkan tidak masuk kerja dalam jangka waktu tertentu (Badilah \& Pardede, 2009). Cuti diberikan dalam rangka usaha menjaga kesehatan jasmani dan rohani karyawan sehingga cuti menjadi hak yang dimiliki karyawan yang telah bekerja dalam periode tertentu (Ariawan \& Wahyuni, 2015). Perkembangan teknologi saat ini memberi dampak yang sangat baik bagi manusia, khususnya bagi sebagian besar perusahaan, di mana teknologi dapat mempermudah kegiatan manusia. Salah satunya teknologi informasi yang ditujukan untuk membantu pekerjaan dengan menyediakan informasi dan melakukan berbagai tugas yang berhubungan dengan pengolahan informasi (Hanum \& Saifudin, 2019). Teknologi ditujukan untuk membantu berbagai jenis pekerjaan manusia untuk meningkatkan kemudahan, efektifas dan efesiensi (Taufiq, Magfiroh, Yusup, \& Yulianti, 2020).

Sistem informasi yang mendukung segala aspek yang diperlukan dalam memberikan sumbangan pemikiran dan karya nyata dalam membangun suatu kinerja sangat dibutuhkan dan diharapakan dalam era persaingan dunia kerja saat ini. Sistem informasi kepegawaian adalah salah satu implementasi teknologi informasi yang sangat banyak diterapkan pada perusahaan (Huda \& Priyatna, 2019). Aplikasi pengajuan cuti merupakan salah satu aplikasi yang vital dalam sistem informasi kepegawaian yang berfungsi untuk mengelola cuti pegawai, dimana pegawai mengambil suatu keadaan untuk tidak masuk kerja dalam waktu tertentu yang diijinkan.

Penelitian tentang pengajuan cuti pegawai banyak dilakukan salah satunya oleh Badilah yang mengembangkan dan membuat aplikasi berbasis desktop untuk program pengajuan cuti pegawai (Badilah \& Pardede, 2009). Hasil penelitian tersebut belum dapat pula menyediakan kesempatan bagi pegawai untuk mengajukan cuti secara online. Penelitian tentang aplikasi pengajuan cuti pegawai secara online sangat penting dilakukan karena memberikan manfaat dalam memberikan informasi dengan cepat, serta memberikan kemudahan bagi pegawai untuk mengajukan cuti dan mendapatkan informasi cuti pegawai. Banyak perusahaan atau kantor masih menggunakan cara yang kurang efektif yaitu menggunakan lembar atau form pengajuan cuti dan memasukkan data tersebut ke dalam sebuah file. Hal ini mengakibatkan rentannya data yang dimasukkan dari kerusakan atau hilang sehingga proses selanjutnya seperti pembuatan laporan membutuhkan waktu.

Berdasarkan pemasalahan tersebut maka penulis melihat sebuah sistem informasi cuti pegawai secara komputerisasi dengan menggunakan web aplikasi yang berbasis database merupakan salah satu solusi pengolahan atau masukan data yang lebih cepat dan akurat dalam pencarian data, pemrosesan data serta penyimpanan data. Diusulkan aplikasi berbasis web karena data dan informasi yang disampaikan melalui website dapat diakses lebih mudah dan tersebar lebih cepat sehingga lebih efisien (Yulianti, Saifudin, Haryono, Zulfikar, \& Desyani, 2020).

Bagian kepegawaian sering kali menghadapi beberapa masalah dalam proses pengajuan cuti yang sering kali dapat menghambat dalam pembuatan laporan (Suharyanto, 2017). Keterlambatan dalam pembuatan surat-surat dan laporan karena masih digunakannya sistem semi komputerisasi dalam sistem informasi cuti pegawai atau karyawan. Kesalahan dalam memasukkan data lambat diketahui karena proses pengajuan cuti atau ijin masih cukup lambat dikarenakan masih berupa form (manual) dan baru kemudian dimasukkan di program berbasis desktop.

Selain dari bagian kepegawaian, permasalahan juga muncul dari sisi karyawan. Karyawan tidak dapat mengetahui jumlah saldo cuti atau ijin yang dapat mereka gunakan (Syaripudin \& Cahyana, 2015). Kesulitan saat pengajuan cuti atau ijin secara mendadak.

Tujuan dari penelitian ini adalah untuk memberikan solusi yang terbaik serta mengkaji dokumen apa saja yang dapat dibuat efisien. Penelitian hanya akan berfokus pada rancangan pengajuan cuti atau ijin kerja berbasis web yang bermula dari analisa program, merancang keluaran sampai akhirnya proses pembuatan laporan. 


\section{Metodologi}

\subsection{Pengertian Sistem}

Sistem adalah kumpulan dari beberapa sub sistem yang saling terintegrasi dan bekerjasama untuk mencapai suatu tujuan baik itu sistem abstrak maupun fisik (Jesa Ariawan dan Sri Wahyuni, 2015). Sistem adalah sesuatu yang terdiri dari beberapa obyek, atau unsur, atau komponen yang saling berkaitan dan berhubungan, sedemikian rupa sehingga menjadi satu kesatuan dari pengolahan data ataupuan pemrosesan.

Sistem dapat didefinisikan sebagai unsurunsur yang saling berhubungan erat suatu unsur dengan unsur yang lainnya dan bersama untuk mendapatkan sebuah tujuan tertentu. Maka pengartian ini dapat dijelaskan secara umum, yaitu:

a. Sistem-sistem yang terdiri atas beberapa unsur.

b. Unsur-unsur dalam sistem merupakan bagian sistem yang saling terkait, masing - masing unsur sistem saling berhubungan erat dan memiliki sifat serta mempunyai bentuk kerjasama tertentu antara unsur tersebut.

c. Di antara unsur sistem bekerjasama untuk mencapai tujuan sistem. Masingmasing unsur sistem mempunyai tujuan tertentu dan dengan suatu proses dapat mencapai tujuan sistem.

d. Suatu sistem merupakan bagian dari beberapa sistem lain yang lebih kompleks dan besar.

\subsection{Pengertian Aplikasi}

Aplikasi ialah suatu hasil dalam bentuk perangkat lunak yang difungsikan untuk pemanfaatan komputer dari user atau pengguna, siap pakai, yang digunakan untuk mendapatkan pencapaian yang sesuai akurat dan dengan tujuan atau fungsi aplikasi itu dibuat. Aplikasi berarti dengan teknisi pemrosesan data mampu melakukan pemecahan masalah dan biasanya bekerja pada sebuah komputansi yang diinginkan atau diharapkan. Dan secara umum aplikasi ialah alat komputer ataupun perangkat komputer yang digunakan secara khusus sesuai kemampuan yang dimilikinya.

Banyak definisi aplikasi yang telah dipublikasikan. Aplikasi adalah penggunaan sebuah komputer, berupa instruksi atau pernyataan yang disusun sistematis sehingga dapat memproses suatu masukan menjadi luaran. Aplikasi adalah software yang dibuat oleh suatu perusahaan komputer untuk mengerjakan tugastugas tertentu, misalnya Microsoft Word, Microsoft Excel. Kamus Besar Bahasa Indonesia mengartikan aplikasi adalah penerapan dari rancangan sistem untuk mengolah data dengan menggunakan aturan atau bahasa pemrograman tertentu yang dibuat agar dapat mengerjakan dan menjalankan tugas spesifik dari pengguna. Wikipedia, aplikasi adalah suatu perangkat lunak (software) komputer yang langsung dapat digunakan dan dimanfaatkan untuk melakukan dan mengerjakan suatu tugas atau perintah yang diinginkan pengguna. Aplikasi adalah media yang bermanfaat untuk menjalankan pengolahan data. Aplikasi adalah perangkat lunak sebagai front end sebuah sistem yang dipakai untuk mengelolah data sehingga menjadi sebuah informasi.Aplikasi merupakan kelompok file yang digunakan untuk mengekseskusi aktivitas tertentu yang saling berkaitan.

\subsection{Definisi Database}

Database adalah basis data atau kumpulan suatu informasi yang disimpan di dalam komputer secara sistematik sehingga dapat diperiksa menggunakan suatu program komputer untuk memperoleh informasi. Untuk mengakses, penambahan, dan pemproses data yang akan tersimpan dalam database komputer maka diperlukan sistem manajemen basis data.

Perkembangan perangkat yang di lakukan secara tradisional berguna untuk pemrosesan file untuk setiap pengolahan data masing - masing, sehingga pada kelompok pengguna dapat menyimpan file-file nya tersendiri. Hal ini mengakibatkan adanya redundancy atau yang disebut sebagai kerangkapan data.

Beberapa masalah yang terjadi akibat redundansi dalam proses penyimpanan data yaitu:

1. Duplikasi data karena adanya pembaruan data tunggal, seperti memasukkan data pada siswa baru beberapa kali disetiap file tempat data berada.

2. Banyaknya ruang memory atau penyimpanan yang tidak dapat digunakan akibat penyimpana dari data yang sama, dan akan menjadi masalah serius apabila database makin besar.

3. Ketidak konsistenan data di beberapa file yang mewakili data yang sama karena adanya 
update di beberapa file tapi pada file lain tidak.

\section{Hasil dan Pembahasan}

Dengan permasalahan yang telah diteliti pada sebuah penelitian sebelumnya, dimana pegawai tidak dapat melakukan pengajuan untuk cuti secara online yang dikarena aplikasi pengajuan cutinya masih belum dapat dioperasikan secara online (pengajuan cuti yang masih berbasis desktop. Keberhasilan pengembangan pada penelitian ini yaitu berkembangnya sebuah fitur pada pengajuan cuti secara online pada akses internet dan aplikasi yang di buat untuk pengajuan cuti. Pada gambar 1 bisa dilihat untuk menjelaskan proses terjadinya pencapaian tujuan. Pada gambar 2 sampai dengan 4 akan menjelaskan tahapan tahapan tersebut yang disesuaikan dengan adanya teknis dalam pembuatan model sesuai dengan metode UML.



Gambar 1 Use Case Diagram Aplikasi Cuti

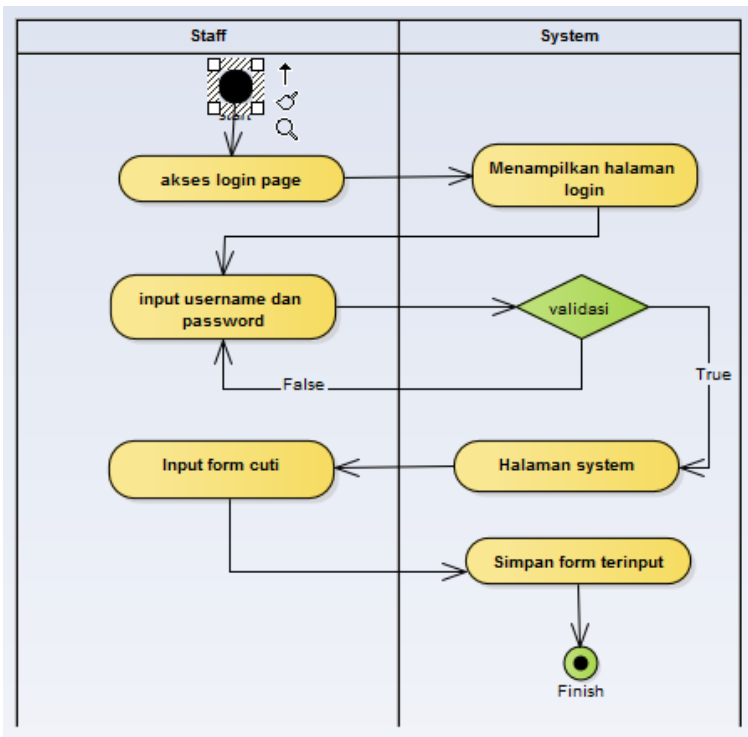

Gambar 2 Activity Diagram Pengajuan Cuti

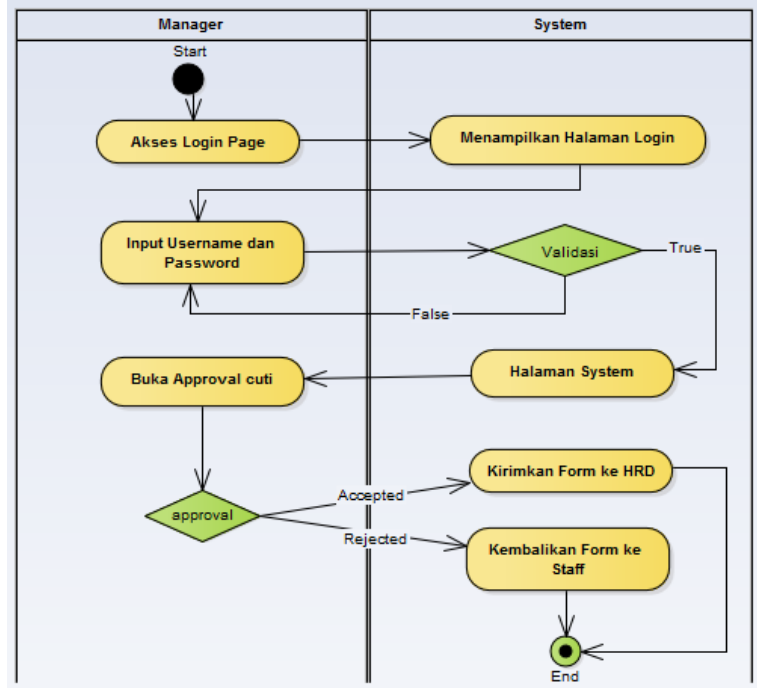

Gambar 3 Activity Diagram Persetujuan Cuti

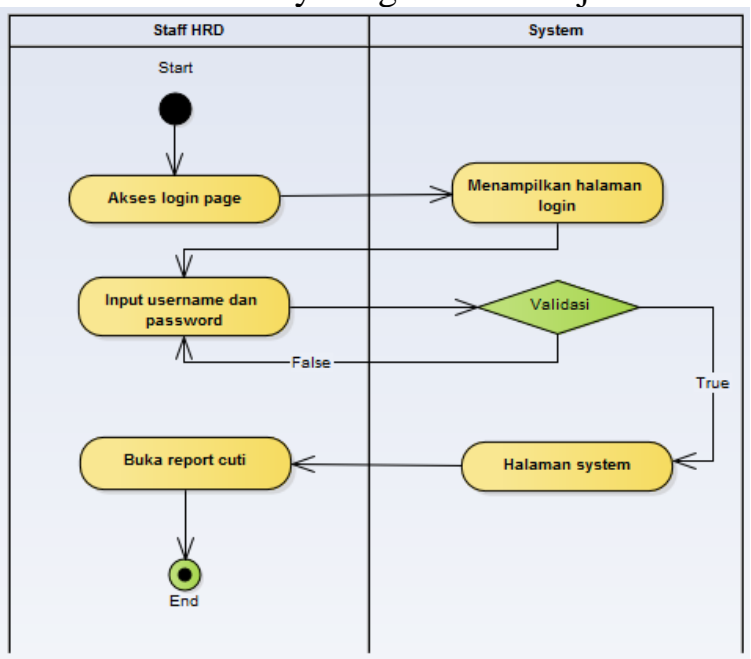

Gambar 4 Activity Diagram Login

\section{Kesimpulan}

Dari rancangan pengembangan aplikasi pengajuan cuti berbasis web serta berdasar kajian atau tinjauan pada teori, maka dapat disimpulkan sebagai berikut:

1. Analisa dan perancangan aplikasi yang dilakukan sebelum pemrograman dapat membantu programmer menerjemahkan persyaratan (requirement) ke dalam bahasa pemrograman yang dapat dieksekusi.

2. Rancangan/desain yang dibuat dapat digunakan untuk mengkomunikasikan pengembangan aplikasi di antara stakeholder.

3. Dengan adanya rancangan maka penguji dapat dengan mudah membuat test case (kasus pengujian)

4. Dengan aplikasi web ini dapat memudahkan kita dalam pengajuan cuti, dikarenakan pada aplikasi ini kita dapat 
mempercepat waktu untuk membuat laporan, mengajukan cuti dan persetujuan cuti dari pihak yang terkait.

5. Persetujuan dari permohonan cuti dapat diketahui dengan waktu yang sangat singkat.

6. Meningkatnya tingkat efisiensi dana atau biaya yang akan di keluarkan oleh perusahaan untuk mencetak form permohonan tersebut.

7. Penyimpanan data yang teratur, aman dan lebih baik karena tersimpan di dalam database serta rancangan user interface juga dapat membantu bagian personalia dalam meminimalkan tingkat kesalahan pengelolaan data cuti yang biasanya terjadi dalam sistem manual.

\section{Saran}

Beberapa saran penting yang perlu diperhatikan yaitu:

1. Sebelum pengembangan aplikasi harus diidentifikasi persyaratan (requirement) dengan baik agar tidak banyak perubahan ketika sedang diimplementasikan

2. Dalam mengembangkan aplikasi berbasis web harus mempertimbangkan penggunaan kapasitas memori yang tersedia pada perangkat yang dituju.

3. Pengembangan aplikasi berbasis web yang baik dilakukan dengan meminimalisir dalam penggunaan bandwidth koneksi internet penggunanya.

4. Perlu dikembangkan proses back-up otomatis untuk keamanan data perlu dilakukan secara berkala sesuai dengan kebutuhan, agar saat terjadi kerusakan data ada backup datanya.

\section{Referensi}

Ariawan, J., \& Wahyuni, S. (2015). Aplikasi Pengajuan Lembur Karyawan Berbasis Web. Jurnal Sisfotek Global, 5(1), 62-66. doi:10.38101/sisfotek.v5i1.67

Badilah, D. F., \& Pardede, D. C. (2009). Aplikasi Cuti Karyawan PT. Bumiputera Capital Indonesia. Jakarta: Universitas Gunadarma.

Hanum, W. S., \& Saifudin, A. (2019). Rancang Bangun Aplikasi Panduan Pariwisata di Kabupaten Banyuwangi Mobile Berbasis Android. Jurnal Teknologi Sistem Informasi dan Aplikasi, 2(2), 59-65. doi:10.32493/jtsi.v2i2.2798

Huda, B., \& Priyatna, B. (2019). Penggunaan Aplikasi Content Manajement System (CMS) Untuk Pengembangan Bisnis Berbasis E-
Commerce. Systematics, 1(2), 81-88. doi:10.35706/sys.v1i2.2076

Suharyanto, C. E. (2017). Perancangan Sistem Informasi Penggajian Terintegrasi Berbasis Web (Studi Kasus di Rumah Sakit St. Elisabeth). Jurnal Teknologi \& Sistem Informasi, Vol. 3 No. 2.

Syaripudin, G. A., \& Cahyana, R. (2015). Pengembangan Aplikasi Web untuk Pengajuan Cuti Pegawai Secara Online. Jurnal Algoritma, 12(2), 526-533. doi:10.33364/algoritma/v.12-2.526

Taufiq, R., Magfiroh, D. A., Yusup, D., \& Yulianti, Y. (2020). Analisis dan Desain Sistem Informasi Pembayaran Sumbangan Pembinaan Pendidikan (SPP) di SMK Avicena Rajeg. Jurnal Teknologi Sistem Informasi dan Aplikasi, 3(1), 15-21. doi:10.32493/jtsi.v3i1.4308

Yulianti, Y., Saifudin, A., Haryono, W., Zulfikar, A. F., \& Desyani, T. (2020). Pengembangan dan Sosialisasi Website untuk Meningkatkan Penyebaran Informasi SMP Islam Madinatul I'lmi Ciputat-Tangerang Selatan. KOMMAS: Jurnal Pengabdian Kepada Masyarakat, 1(1), 16-24. 